\title{
Mobile Computing Framework for Student Engagement System in Ethiopian Higher Educational Institution
}

\author{
Patrick Cerna \\ Department of Information Technology, Federal Technological Institute University, Addis City, Ethiopia \\ Email address: \\ pcerna@acm.org
}

To cite this article:

Patrick Cerna. Mobile Computing Framework for Student Engagement System in Ethiopian Higher Educational Institution. International Journal of Wireless Communications and Mobile Computing. Vol. 6, No. 1, 2018, pp. 10-19. doi: 10.11648/j.wcmc.20180601.12

Received: January 2, 2018; Accepted: January 12, 2018; Published: February 1, 2018

\begin{abstract}
Students require a great deal of information from colleges such as admission notices, timetables, events details, assessments etc. Currently, this information is provided to students through college website. The information present on website is generic, pertaining to large group of students and other stakeholders. Currently in Ethiopia, Higher Educational Institution (HEI) information is distributed to students in two ways, one using traditional paper means and other is using its University website. However, the major challenge in obtaining information from website is that it provides collective information pertaining to large groups of students instead of focusing to individual student needs. In view of this problems and issues concerning the accessibility on on-time information of student in different higher educational institution of the country. In this study, the researcher propose a mobile educational framework student engagement information system coin as mSEIS, integrating the existing web-enabled system of the University and include other features pertaining to student services. The proposed framework and its implementation will empower student by providing them with relevant personalized information anywhere anytime. The study proposed extensible 3-tier architecture from its formulated mobile framework which consists of the following functionality: Grades Inquiry, Class time table, m-Learning, m-Library, Notice Board and Helpline. Among the 40 Ethiopian, HEI 6 institution was selected using purposive sampling technique because the goal of the study was to acquire the best-positioned and the most able thinkers on the problem. Using the Software Quality ISO 9126 standard based modified Likert survey questionnaire, the respondents strongly agreed that the acceptability factor of the system's functionality, reliability, efficiency, usability, maintainability and portability are significant. The proposed system passed all criteria except the portability, in which it is recommended that it should be available in iOS and Windows Phone mobile operation system as future work.
\end{abstract}

Keywords: Mobile Application, Student Engagement, HEI, Three-Tier Architecture, Android

\section{Introduction}

Nowadays, mobile technologies are becoming increasingly ubiquitous and networked. Such technologies can be used creatively in different areas. Using mobile technologies in education is a clear example of such innovation. Mobile devices equipped with internet connections have created the need for a new form of electronic learning, called mobile learning. Internet-enabled mobile devices can help students to access learning resources and online courses, anywhere and at any time [1]. Today it is imperative to not only use the traditional forms of communication, but also newer forms such as mobile technology for quicker and easier communication among the students. In a real world scenario such as college campus, information is provided in the form of notices, hand written manuals, oral communication is spread among the students [2]. So to provide all this information at ease, we are developing this application wherein students can access this information using their Android enabled mobiles. So now students need not queue up near the notice board or log on to college website for any of the abovementioned details.

Ethiopian higher education institution (HEI) has long been regarded as a public good in terms of producing enormous externalities, benefiting not only the individual, but also the society at large [3]. With more than 110,000 students (2016), Ethiopia's private higher education (PHE) is the largest or second largest in sub-Saharan Africa. This large private 
presence exists despite Ethiopia being rather late to start PHE and despite some stiffly restrictive regulation. Higher education in Ethiopia was considered by participants as essential for the growth and development of the country. The importance of quality in the delivery of higher education was recognized by all participants [4]. However, participants strongly indicated that rapid expansion for the sake of opening access, despite inadequate infrastructure and resources, could negatively affect the quality of education in the country [5].

In recent years, mobile devices have become very popular among student community [6]. Using mobile technology; the information can travel to the student in a fast, personalized, accurate and convenient way. The dependency of students on mobiles has resulted in availability of different kinds of mobile apps that provide information, which is custom, tailored to student s needs. Major International universities provide their apps to students for catering to their information requirements [7]. The apps have a studentcentric focus which improves the student's satisfaction with college services [8].

Changes in Information Technology (IT) allow schools to utilize databases and applications thus, making the accessing of records centralized. One of the changes that came about is the online-based applications. These applications are an improvisation to the traditional- transaction processing systems. Thus, most universities switch to the online system because of its efficiency to acquire, process, store and retrieve information from the Internet. Students require lot of information from colleges such as admission notices, timetables, events details, etc. [9].

Students require a great deal of information from colleges such as admission notices, timetables, events details, assessments etc. Currently, this information is provided to students through college website. The information present on website is generic, pertaining to large group of students and other stakeholders. For instance, the notices displayed on websites are not only specific to students, but, notices for teachers, staff members and general public are also provided through the website. Students have to extract their own information from website by navigating through various links or applying many filters/ search criteria. Many students face difficulty in doing so, which results in delivering incomplete or inaccurate information and thus lead to student dissatisfaction. Students are the key stakeholders for any educational institution. In today's competitive environment those educational institutions flourish which develop significant relationship with their students. An information system, which can provide individualized services to students by use of latest technology, can increase popularity of institution [10]. Thus, Mobile information systems are extending the possibilities for when and where to perform learning for different communities.

Currently in most if not all universities in Ethiopia, information is distributed to students in two ways. In traditional approach, notices are displayed on physical notice boards of University which students check on regular basis. It leads to over-crowded notice board areas. Students cannot receive the information if they are not physically present in college. Second approach is to provide information on University websites. Students may access website from anywhere. It does away with crowded notice boards and promotes paperless information dissemination. But, the major challenge in obtaining information from website is that it provides collective information pertaining to large groups of students. The onus of filtering the personalized information and performing calculations to do analysis is on the students.

Unlike web development, mobile development can be more easily extended to end users. This presents institutions with a unique opportunity to involve students in the mobile app development lifecycle. Selecting a mobile platform that provides an easy-to-use app development GUI augments this strategy. Engaging students in the mobile app development lifecycle positions institutions to provide a better student experience, one that is informed by students - if not built by or with them. This means that the campus mobile app must integrate with existing applications - ERP, LMS, Library, and Dining Services - and re-present the web functionality in the form of native mobile apps - app for registration, app for course assignments, app for searching library, app for today's lunch menu. If an institution isn't providing these mobile apps, it is losing the opportunity to attract, engage and retain its customers - students. With most users using their smart phones for communicating and accessing news, delivering messaging functionality is key to a campus mobile app strategy. Targeting news, announcements and alerts to students and tracking the effectiveness of those communications is imperative not only to student success but to student retention [11].

In view of this problems and issues concerning the accessibility on on-time information of student in different higher educational institution of the country, the researchers propose a mobile educational framework student engagement information system coin as mSEIS, integrating the existing web-enabled system of the University and include other features pertaining to student services. The proposed framework and its implementation will empower student by providing them with relevant personalized information anywhere anytime.

\section{Related Works}

Zirra et al [12] proposed an online application for the Training and placement department. This System meant to give more easiness to the users that they can add and retrieve information so quickly. Once you open this web application at the front end all the schedule/event are available to everyone. Also in the every current student login this schedule/event are available. Students on placement will also use the system to read important announcements, to obtain information on assessment, to see the results of assessments recorded in the system.

Pacio [9] develop an online Student Information System that aims to improve the efficiency in managing and 
maintaining student information, thus translating to a better student services for Benguet State University. The system create a new way of record management and transaction processing that would achieve efficiency on processing student infomation. It would be a great help to the administrative personnel, academic personnel, grantors or stakeholders, parents and students in updating, retrieving and generating student data [9]. Similarly, Cantos et. al [13] develop a Mobile Web-Based Student Integrated Information System. to help the students check their academic result every end of the semester, make self-enlistment that would assist the students to manage their academic status that can be viewed intheir mobile phones. The researchers applied Hill Climbing Algorithmsearch technique for the system particularly in creating self-enlistment and finding the best set of courses to the classschedule, and in projection of number of sections to be created for the next semester [13].

Vashi [14] proposed the application where student can get the information such as displaying notices, results, attendance timetables, etc. With the help of this application, not only students can access the information from a remote place but also can avoid the inconvenience of travelling all the way to the institute. This system will benefit the students and help them utilize time effectively. At some colleges certain data is passed onto the students using SMS facility. But this transfer is only on the side of college. It doesn't take into consideration which information is needed by which student and at what time. Also the delivery of the SMS to the students is based on the student's mobile network. The college website which partially displays the information is heavy and requires flash, java, shockwave player and more time for loading content. Dadape et al [15] proposed the android mobile application called MOBILE-CAMPUS, with which mobile users can get valuable information on different landmarks of a university campus and guide students/parents/visitors to find the desired places in campus with more ease anytime and anywhere. To develop this application they have used java programming language, which is used for android platform applications

Recently, many researchers have focused on mobile learning and its environment. Some researchers have defined the difference between e-learning and mobile learning, saying that e-learning is a learning process which is supported by digital electronic tools and media, and by analogy, m-learning is e-learning that uses mobile devices and wireless transmission [16]. Hashim et al [17] introduced a Java m-learning application tool to review and revise course materials. This application can be used either on-line or off-line. The on-line feature helped users to access learning material through a certain URL, while the off-line feature helped users to access learning content via the application, which had been installed on their mobile devices. This application mainly focused on three subject areas: Science, English, and Mathematics. Learners could use the application to review course materials before exams or quizzes.

In light of the above literature, the researchers identify gaps of the current limitation of Ethiopian higher educational institution website access to information that support student services. With this, the researchers concluded that is a need to transfer website contents and other supporting features into a mobile application to satisfy the information needs and avail support services to improve their academic setting.

\section{Materials and Methods}

\subsection{Research Design and Sampling}

Research methodology is a means through which solution or solutions to research problems or questions could be found [18]. This study employed a descriptive developmental method of research design. Descriptive method was used in discussing the results of the testing phase while the development method was used during the system development. In order to back up the set of findings from the data collection in one method underpinned by different methodologies, quantitative and qualitative research methodologies were used together in analysing the usefulness of mobile student information system supporting daily task of Ethiopian HEI.

According to MoE [19], there has been over 40 public HEI in Ethiopia with categories within 1st generation, 2nd generation and 3rd generation universities. Among this population, 6 out of this $40 \mathrm{HEI}$ was selected using purposive sampling technique because the goal of the study was to acquire the best-positioned and the most able thinkers on the problem. It was selected based on their relatively higher enrolments, proximity of location, ICT infrastructure supporting services, and modes of educational service deliver. Each of the 6 selected institutions was asked to contribute two group of respondents namely teacher and students. A Slovin's formula was used to determine the sample size comprising the above-mentioned group of respondents, which generated about 90 participants out of a larger population combine student and teachers as reflected in Table 1.

Table 1. Ethiopian HEI Population and Sampling.

\begin{tabular}{llll}
\hline No & Higher Education Institution & Target Group & Sample \\
\hline \multirow{2}{*}{1} & \multirow{2}{*}{ Haramaya University } & Student & 20 \\
& & Teacher & 4 \\
2 & Dire Dawa University & Student & 15 \\
& & Teacher & 3 \\
3 & Hawassa University & Student & 10 \\
\multirow{2}{*}{4} & \multirow{2}{*}{ Metu University } & Teacher & 2 \\
& & Student & 10 \\
5 & \multirow{2}{*}{ Arsi University } & Teacher & 2 \\
& & Student & 10 \\
6 & \multirow{2}{*}{ Federal Technological Institute - University } & Teacher & 2 \\
& TOTAL & Ttudent & 10 \\
& & & 2 \\
\hline
\end{tabular}

\subsection{System Overview}

The software development methodology used in the study was Rapid Application Development (RAD). RAD technique 
allows "Rapid" application development, with development time to 30 or maximum of 90 days. However, RAD approach is concerned with few comprises usability, features, and execution speed [20]. (Rapid Application Development $(\mathrm{RAD})$ is an object - oriented approach to systems development that includes a method of development as well as software tools [21]. Android Studio was the Integrated
Environment Development (IDE) of the system, which is very effective when developing android mobile application. Furthermore, REST web services was utilized services that fetch the personalized information of student from database based on students unique id and then send individualized data to presentation layer in XML/ JSON format shown in the mobile devices.

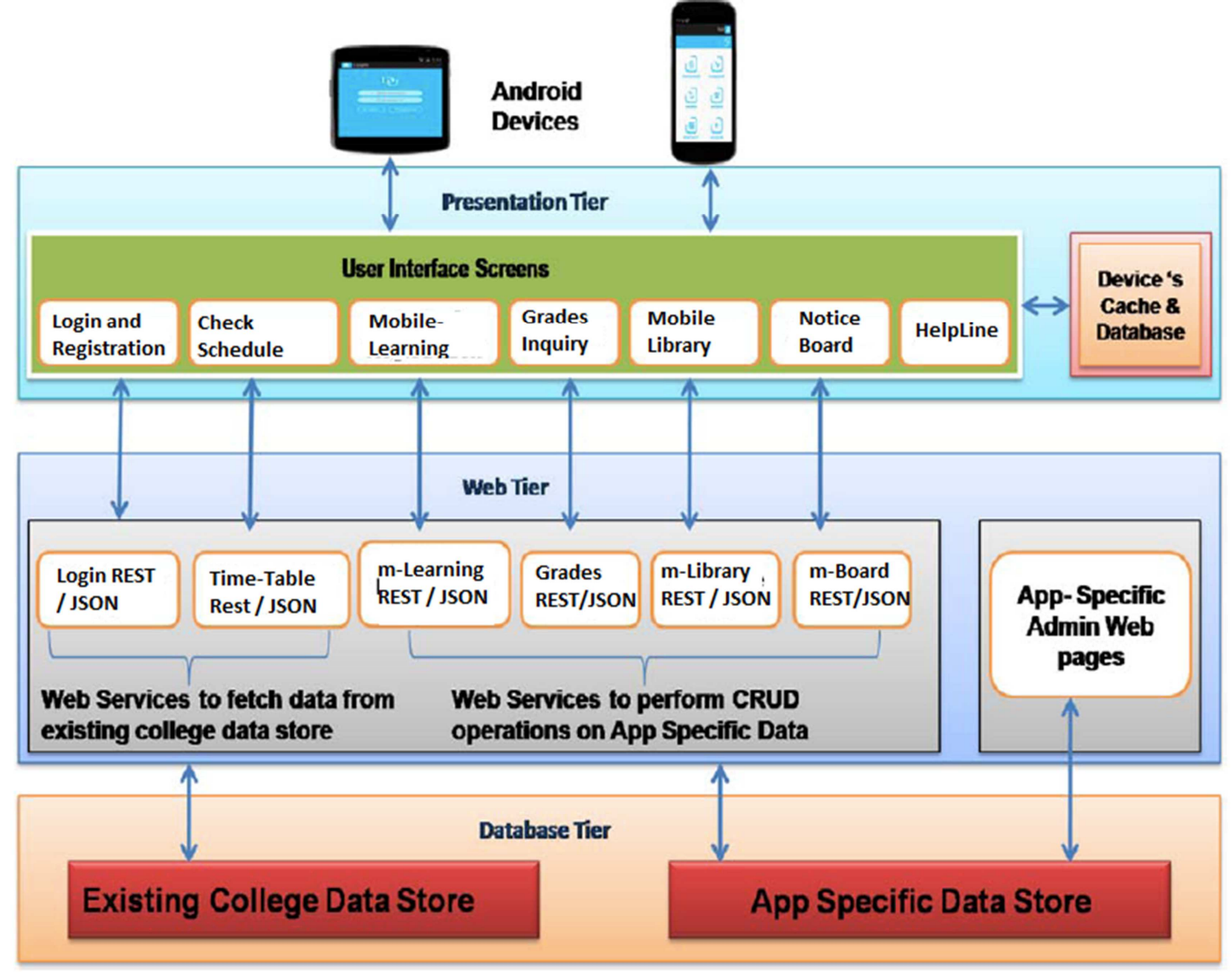

Figure 1. Mobile Framework of mSEIS.

Figure 1 proposed the Mobile Framework of mSEIS for Ethiopian HEI. For each component there are distinctive user interface screens, which interact with web services to retrieve data from the University database. A brief description of each component is as follows:

A. Login and Registration- New user registers first by entering their id number, email id and password. Subsequently, the student logs in to access Mobile Student Engagement System and access other features/services of the apps.

B. Time-Table and Schedule - this module enable the students to check their daily time-table based on the courses they have taken every semester.

C. m-Learning - this tool enable the student to access existing LMS hosted in moodle. This will help view and download relevant course materials within their mobile devices.

D. Grades Inquiry - Student after registration may be able to access their grades as integrated to the existing Universities student registrar information system.
E. Notice Board -A list of notices is displayed. By tapping on the particular notice, detailed information can be viewed. This can be university announcement, college announcement and/or from the instructor itself.

F. Library Services - This tool enable the student to access existing University ICT library resource like OPAC, DSpace thesis and Dissertation repository, and the like. This will run this system into mobile apps.

G. Helpline-Helpline provides a call-on-click feature to connect to University Information Center which provides information services to the students and resolves their queries. Call-on-click option is provided for offices of University affiliated hospital and the like.

When a completely new application is designed, a lot of effort goes into its development and testing to come up with a stable product. Reuse of existing resources offers various benefits in terms of reducing time, cost and effort involved in developing an application. Reuse is the practice of incorporating an asset in more than one system [22]. Most educational institutions including Ethiopian HEI already have 
their web based information systems in place which means they have web server/application server on which the web site is hosted and a database containing all college-related data (including student Data). If reuse existing infrastructure and software, existing processes do not get much impacted and we mainly focus on stabilizing the new features. Also, by using service-oriented architecture, self-contained web services for different components of required information system, they can be reused by different consumer applications across multiple platforms by putting in very little extra effort. Keeping in mind the benefits of 'Service Oriented Architecture, and 'Reusability', this research proposes extensible3-tier architecture to develop mobile applications for student information system as shown in Figure 2.

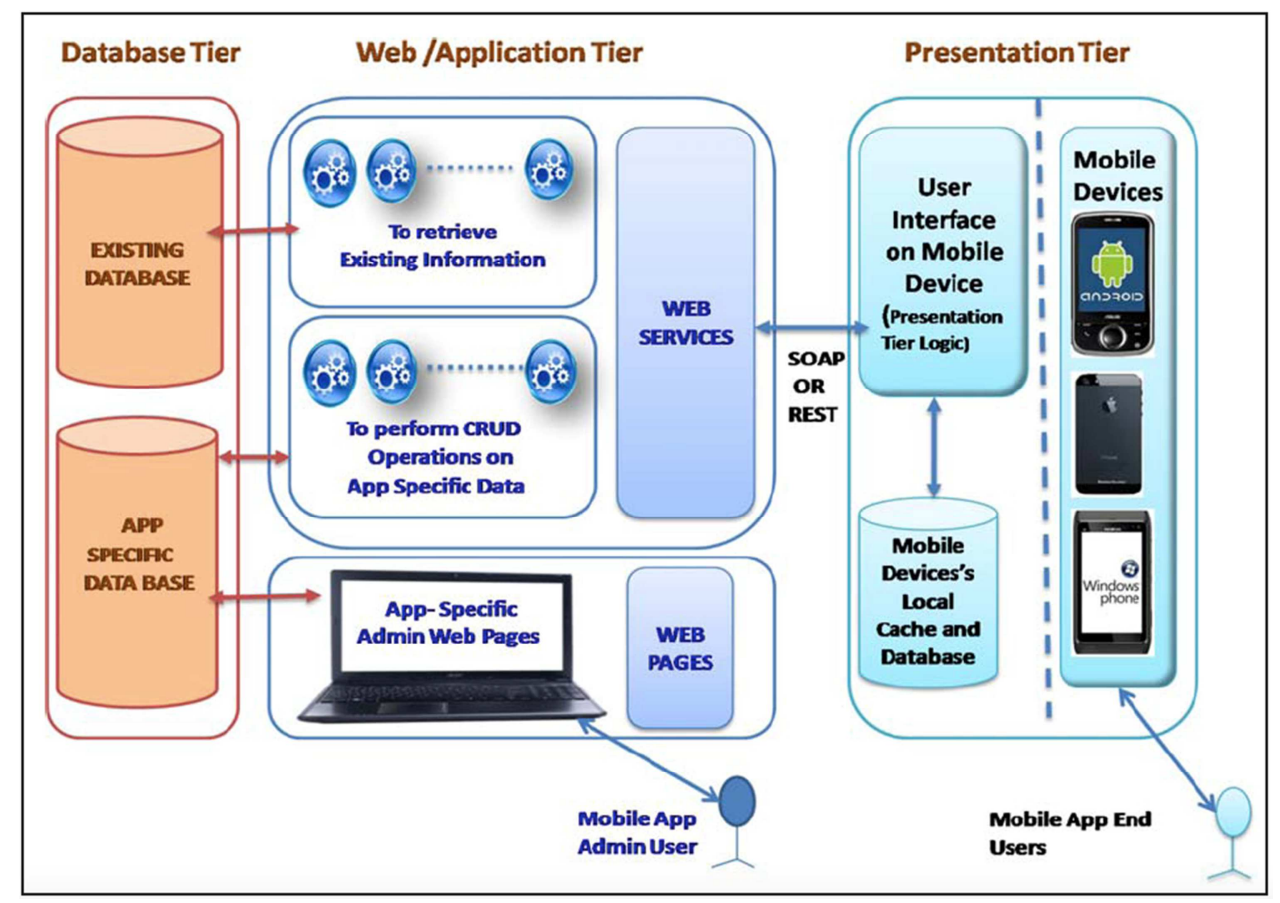

Figure 2. Three tier architecture of Mobile Student Engagement System.

The components of the architecture in detail as discuss below:

1. Database Tier

Database tier is composed of two data stores. One is the existing database of educational institution from which student related information is fetched. Since we perform only retrieval of data from this database and do not modify it, it can be used by web based information system or in any other way as it was previously being used. A small separate database component is created to add some app-specific data such as list of registered users of the app, records of external links to web pages etc. Create, Read, Update and Delete (CRUD) operations are performed on this database as this is specific to the mobile app.

2. Web/Application Tier

We develop web services and admin web pages for mobile app in this tier. Web services are broadly categorized into two groups. First group includes the services that fetch the personalized information of student from database based on students unique id such as enrollment number. These services do not perform any create/update/delete operation and perform only read operation on existing database of institution. These services send individualized data to presentation layer in XML/ JSON format. Second group of web services performs CRUD operations on app specific data store. They transfer data to and fro from mobile app to data store using XML/JSON. Additionally, admin web pages are created in this layer, which are accessed by University admin Department. Using these pages, college admin department manages the configuration of various component of app.

3. Presentation Tier

At the Presentation tier, we have cross platform mobile devices, on which app is to be deployed. The presentation layer logic is platform dependent and is written uniquely for devices of different platforms. This logic creates the appropriate user interface screens on the device. Moreover, this layer acts as a consumer of web services created at middle tier. It registers new users and requests student $\mathrm{s}$ information by calling web services. Web services in turn interact with database and deliver data to this layer in $\mathrm{XML} / \mathrm{JSON}$ format. The response is parsed to fetch the desired information which is finally presented to the users. Cache and local database of mobile is used to store application data.

\subsection{System Design}

The system is an android based mobile app developed using the proposed architecture is divided into six main menu pertaining to Time Table, Mobile-Learning, Grades Inquiry, Mobile Library, Notice Board, and Help Line as shown in Figure 3. There is also a login and registration component that enables registration of new user and access to app by registered users as shown in Figure 4. 


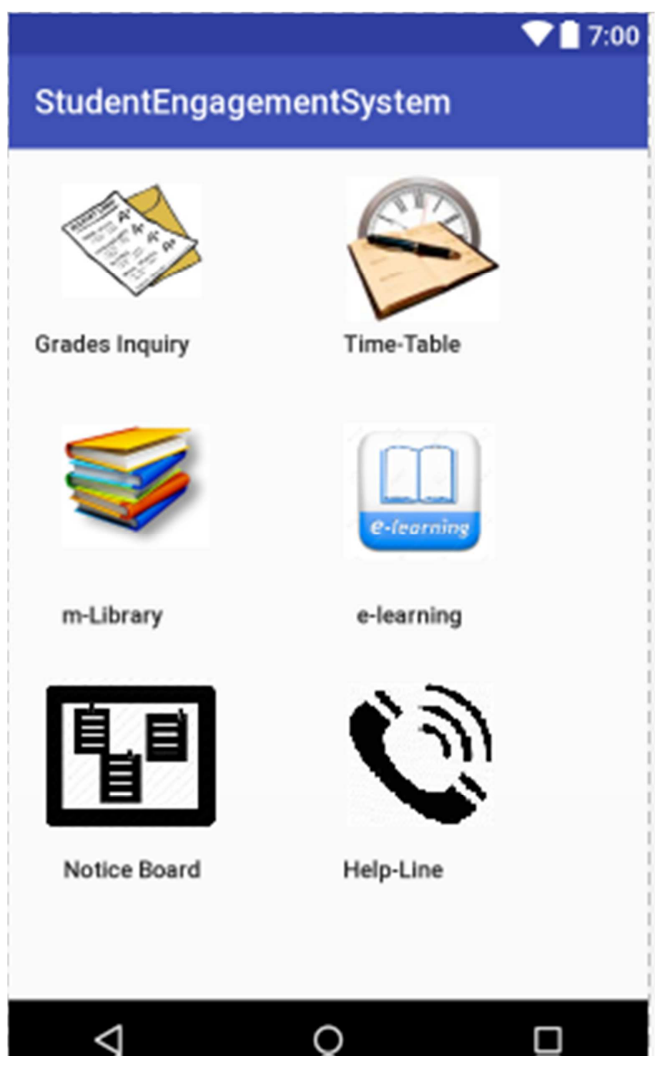

Figure 3. Main Interface of mSEIS.

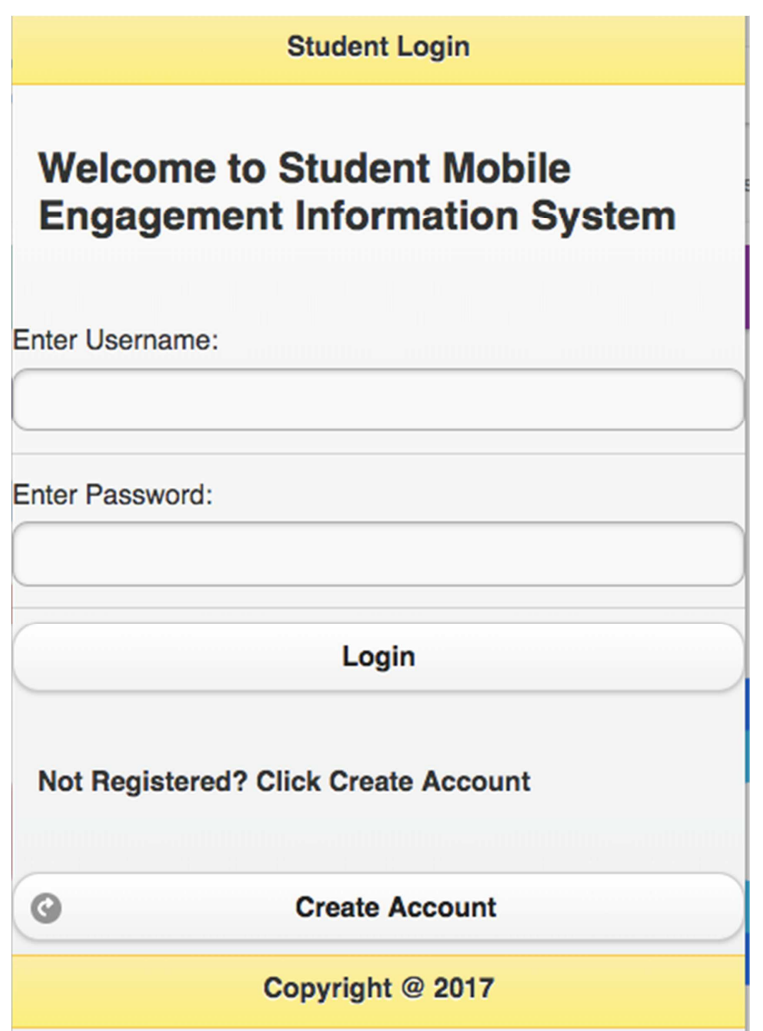

Figure 4. Login and Registration Menu.

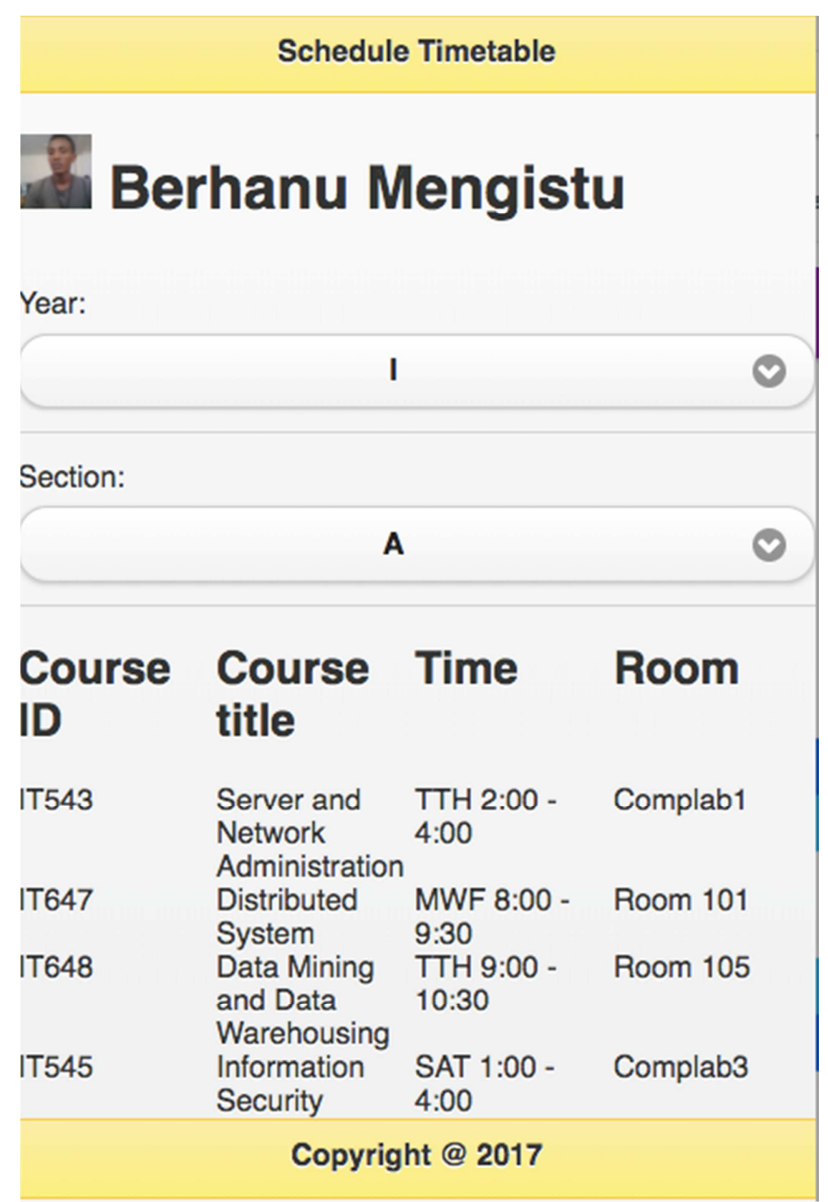

Figure 5. Class Time Table. 
Figure 5 shows the class schedule time-table of each course in a semester for easily access among the HEI students within their mobile devices. While Figure 6 shows the m-learning connected the e-learning management system of a HEI for access learning materials both by instructors and students.

Another mobile services useful for student researchers is to be able to scan for journal articles, books and related documents. Figure 7 shows the mobile interface of m-Library OPAC reflected as mobile apps engaging research activities of students. While Figure 8 shows mobile grade inquiry to for easy retrieval of grades among the HEI students through their mobile devices.

\section{m-Learning}

\section{Berhanu Mengistu}

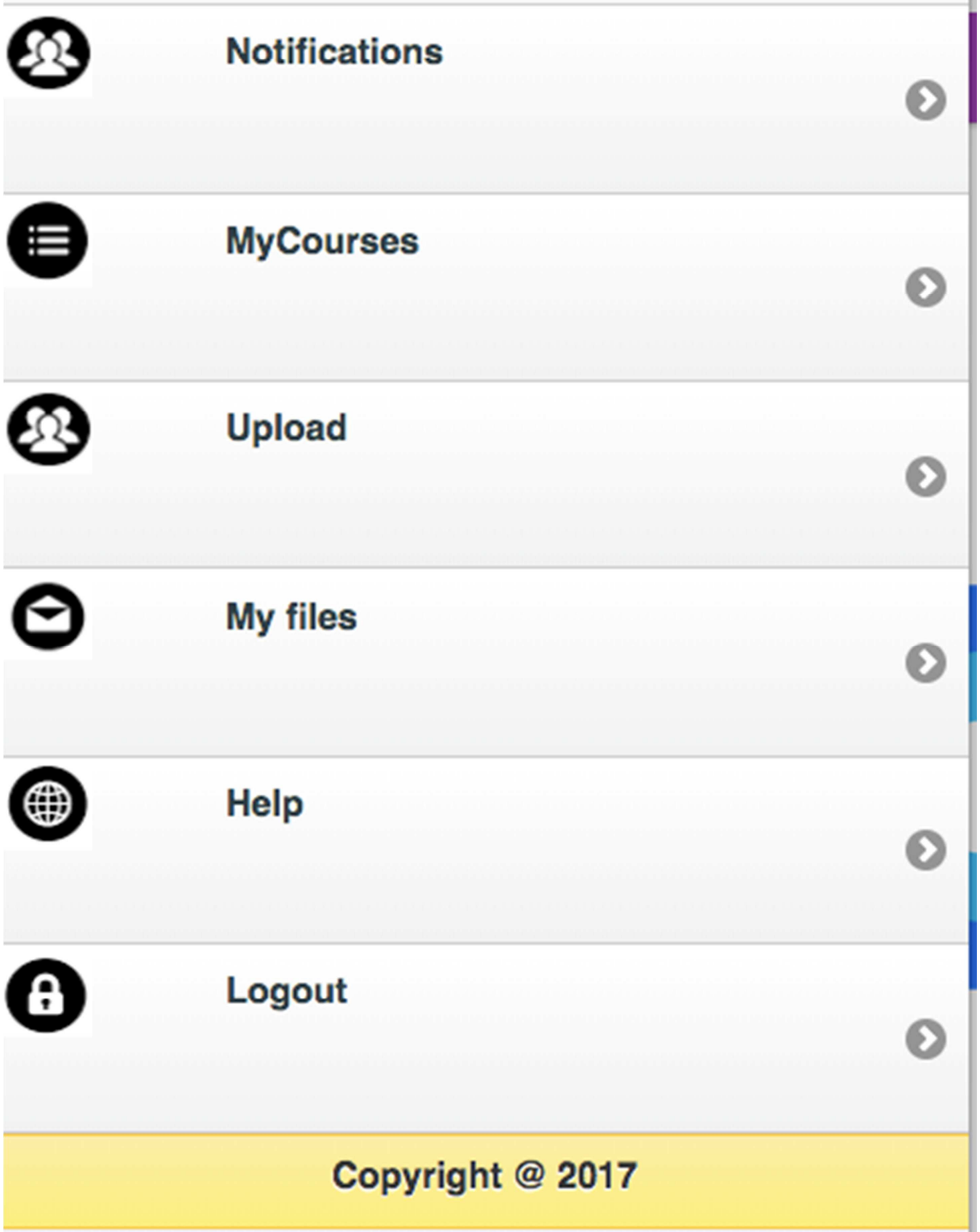

Figure 6. Class Time Table. 
m-library Services

\section{Mobile OPAC}

Enter Keyword:

Internet of Things

Filter by:

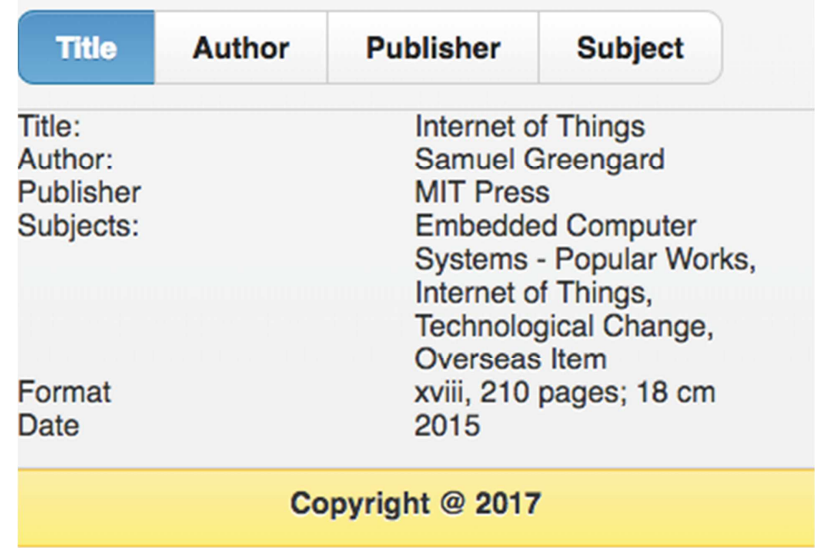

Figure 7. Mobile Library OPAC as Mobile Apps.

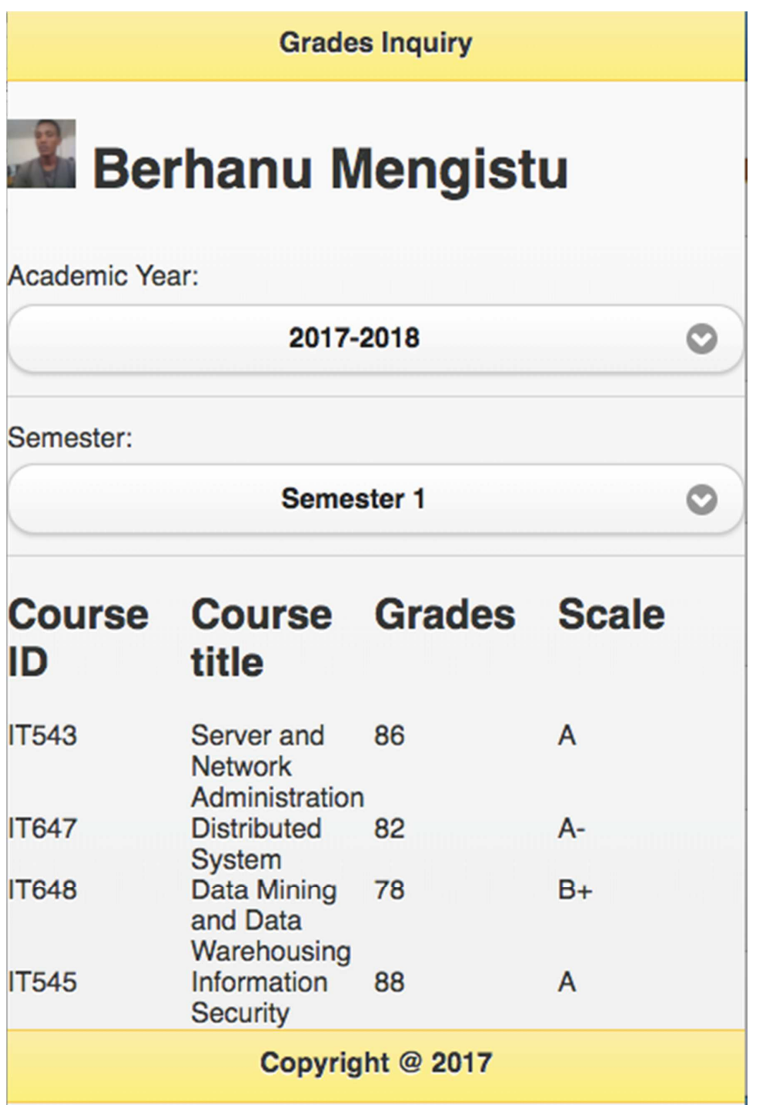

Figure 8: Grades Inquiry. 


\section{Results and Discussion}

The mobile application was tested using Samsung Galaxy J3 running Android Operation System 6.0 (KitKat). The evaluation of the system involved 90 respondents combine teachers and staff in selected 6 HEI in Ethiopia. The proponent used ISO 9126 based Likert modified scale type of questionnaire. The evaluation assesses the system acceptability in terms of functionality, reliability, usability, efficiency, maintainability and portability. The "functionality" criterion measured the system's attribute in terms of suitability, accurateness, interoperability, compliance and security. "Reliability" is evaluated by maturity, fault tolerance and recoverability yielded by the system. "Usability" refers to the user's understandability, learnability, operability and attractiveness of the system. "Efficiency," on the other hand, depends on the resource utilization and time behavior. "Maintainability" is assessed by analyzability, changeability, stability and testability of the system. Lastly, "portability" refers to the adaptability, installability, conformance and replaceability of the system.

Table 2 shows the result of evaluation on the functionality, reliability, usability, efficiency, maintainability and portability of the system. Majority of the respondents strongly agree as presented by the result that the system operates with minimal human intervention supporting student mobile services like e-learning, m-library, check grades and schedule based on the Functionality Mean value of 4.61. In addition the results shows that in terms of reliability (4.62), usability (4.61), efficiency (4.66), and maintainability (4.60), majority of the respondents strongly agree and pass the mentioned criteria. However, as evident from the results that in terms of portability (2.32), majority of the respondents that it did not pass the criteria, and the apps should support other mobile operation system.

Table 2. User Acceptance Testing of mSEIS.

\begin{tabular}{|c|c|c|c|}
\hline \multicolumn{2}{|c|}{ System Acceptability Criteria } & \multirow[t]{2}{*}{ Mean } & \multirow[t]{2}{*}{ Interpretation } \\
\hline A. $\mathrm{I}$ & & & \\
\hline 1) & The system performs m-learning accessing learning materials and modules. & 4.62 & Strongly Agree \\
\hline 2) & The system checks and shows the time-table for every course in a semester & 4.71 & Strongly Agree \\
\hline 3) & The system help student researcher's access library services in mobile devices. & 4.56 & Strongly Agree \\
\hline 4) & The system shows the grades of the courses enrolled in previous semester. & 4.62 & Strongly Agree \\
\hline 5) & The system post updated notice and accessible to everyone. & 4.56 & Strongly Agree \\
\hline 1) & The system is capable of handling incorrect inputs & 4.58 & Strongly Agree \\
\hline 2) & The system is free from bugs and runs smoothly without interruption & 4.64 & Strongly Agree \\
\hline 3) & The system can recover from failure and can resume operations & 4.68 & Strongly Agree \\
\hline 4) & The system easily find the information I am looking for using the system & 4.71 & Strongly Agree \\
\hline 5) & The software can recover even after failure & 4.51 & Strongly Agree \\
\hline \multicolumn{4}{|c|}{ C. Usability } \\
\hline 1) & The system to easy to use (user - friendly) & 4.76 & Strongly Agree \\
\hline 3) & Navigation on the different modules is easy & 4.55 & Strongly Agree \\
\hline 4) & The system is available for free download and transferable to other android phone & 4.59 & Strongly Agree \\
\hline 5) & The system can be used even if the users don't have technical experience & 4.53 & Strongly Agree \\
\hline \multicolumn{4}{|c|}{ D. Efficiency } \\
\hline 1) & The system responds instantly & 4.65 & Strongly Agree \\
\hline 2) & The system processes data quickly & 4.78 & Strongly Agree \\
\hline 3) & The system can generate report quickly & 4.63 & Strongly Agree \\
\hline 4) & The system instantly responds to command of the user & 4.68 & Strongly Agree \\
\hline \multirow[t]{2}{*}{ 5) } & The system filter out precise information based on criteria & 4.59 & Strongly Agree \\
\hline & E. Maintainability & & \\
\hline 1) & Errors can be easily detected by the system & 4.64 & Strongly Agree \\
\hline 2) & The application can be easily modified & 4.63 & Strongly Agree \\
\hline 3) & The application can continue functioning if changes are made & 4.51 & Strongly Agree \\
\hline F. & Portability & & \\
\hline 1) & The apps can be moved to other environments & 2.2 & Disagree \\
\hline 2) & The apps can be deployed easily & 2.1 & Disagree \\
\hline 3) & The apps complies with portability standards & 2.2 & Disagree \\
\hline 4) & The apps can be share to other android smart phone & 4.1 & Strongly Agree \\
\hline 5) & The apps is available in other mobile operating system & 1.00 & Strong Disagree \\
\hline
\end{tabular}




\section{Conclusion and Recommendations}

\subsection{Conclusion}

The respondents specifically the viewing of schedule of students that is generated automatically and the projection of number of sections for the next semester emphasize the potentials of the system in terms of functionality, reliability, usability, efficiency, maintainability, and portability. In this experimental study, the researchers propose mobile application student engagement information system by integrating the existing web-enabled system of University and include other features pertaining to student services. The researcher is confident that the results of the study are deemed beneficial to the following stakeholders. These stakeholders are the primarily for students, academic staff, administrator and university officials. It will speed up the dissemination of information, improve accessibility, and generate satisfaction on student related services. Furthermore, the resulting system of the study will provide avenue for the improvement of future related studies on application of mobile computing in academic activities Ethiopian HEI.

\subsection{Recommendations}

The respondents strongly agreed that the acceptability factor of the system's functionality, reliability, efficiency, usability, maintainability and portability are significant. The proposed system passed all criteria except the portability, in which it is recommended that it should be available in iOS and Windows Phone mobile operation system as future work. Finally, further work is expected to include other features to support student like location mapping, dormitory management, student meal cafeteria management, sport activities, among others.

\section{References}

[1] Fu, F.-L., Su, R.-C., and Yu, S.-C. (2009) 'EGame Flow: A scale to measure learners' enjoyment of e-learning games', Computers\& Education, 52 (1), pp. 101-112. [Online].

[2] Harnale S., Ganeshsingh T., Hussain, S. A. (2014). "Android College Campus", International Journal of Ethics in Engineering \& Management Education, ISSN: 2348-4748.

[3] Nega, M. (2017). The Public-Private Divide in Ethiopian Higher Education : Issues and Policy Implications, 5 (4), 591599 .

[4] Tamrat, W., \& Levy, D. (n. d.). Unusual in Growth and Composition : Ethiopian Private Higher Education, 19-21.

[5] Yirdaw, A. (2016). Quality of Education in Private Higher Institutions in Ethiopia. SAGE Open, 6 (1), 215824401562495 .

[6] Norazah MohdSuki, (2013). Students dependence on smart phones, Campus-Wide Information Systems, 30 (2) 124-134.

[7] Shilpi, Taneja., Goel, Anita. (2015). Mobile Applications in Educational Institutions. Computational Intelligence \&Communication Technology (CICT), 2015 IEEE
International Conference on. IEEE, 2015.

[8] Asif, Muhammad., Krogstie, John. (2011). Mobile student information system, Campus-Wide Information Systems, 28 (1) $5-15$.

[9] Pacio, R. (2014). Online Student Information System Of Benguet State University (OSIS-BSU). Auamii. Com, (4), 17. Retrieved from

http://www.auamii.com/proceedings_Phuket_2012/Rochelle Pacio.pdf

[10] Elaine, D., O'Hara, Seeman Margaret. (2006). Customer relationship management in higher education, Campus-Wide Information Systems, 23 (1) 24-34.

[11] Educause Review (2017). Engaging Students with a Mobile App. Accessed in http://er.educause.edu/articles/2015/3/engaging-students-witha-mobile-app.

[12] Zirra E., March F., Building University - Enterprise Cooperation for the Benefit of Students, Enterprises and Companies. EUI-Net workshop, Athens 28 September (2006).

[13] Cantos, M. C. G., Rabago, L. W., \& Tanguilig, B. T. (2015). Mobile Web-Based Student Integrated Information System. International Journal of Machine Learning and Computing, 5 (5).

[14] Vashi, Navi (2012). "A Mobile Application to Access Remote Database using Web Services", Proceedings of the NCNTE2012, Third Biennial National Conference on Nascent Technologies Fr. C. Rodrigues Institute of Technology.

[15] Dadape, Jinendra R. Jadhav, Bhagyashri R. Gaidhani Pranav Y. Vyavahare Seema U. Achaliya Parag N, "Smart Travel Guide: Application for Android Mobile", 1st International Conference on Recent Trends in Engineering \&Technology, Mar-2012Special Issue of International Journal of electronics, Communication \& Soft Computing Science \& Engineering, ISSN: 2277-9477.

[16] Pinkwart, N., et al. (2003) 'Educational scenarios for cooperative use of Personal Digital Assistants', Journal of Computer Assisted Learning, 19 (3), pp. 383-391.

[17] Hashim, A. S., Ahmad, W. F. W. and Ahmad, R. (2011) 'Mobile learning course content application as a revision tool: The effectiveness and usability', Pattern Analysis and Intelligent Robotics (ICPAIR). Tronoh, Malaysia, 2001. Computer \& Informatics Science Department, University of Teknol: pp. 184187.

[18] Goddard, W. and Melville, S. (2005). Research Methodology: An Introduction. Lansdowne: Juta and Company Ltd.

[19] MoE (2017). Ministry of Education-Higher Education Subsector. Retrieved from http://www.moe.gov.et/highereducation-admission.

[20] Kaatib, A. (2005). Rapid Application Development: IS it really a need today? Retrieved from www.ezinearticles.com

[21] Kendall, K. And Kendall, J. (2005). System Analysis and Design. Sixth Edition. Pearson Education Pte Ltd.

[22] Rada, Roy. (2001). Levels of reuse in educational information systems, Campus-Wide Information Systems, 18 (3) 103-109. 